Research Article

\title{
Construction and Validation of a Convenient Clinical Nomogram to Predict the Risk of Brain Metastasis in Renal Cell Carcinoma Patients
}

\author{
Yuexin Tong, ${ }^{1}$ Zhangheng Huang, ${ }^{1}$ Chuan Hu, ${ }^{1,2}$ Changxing Chi, ${ }^{3}$ Meng Lv, \\ and Youxin Song $\mathbb{( i )}^{1}$ \\ ${ }^{1}$ Affiliated Hospital of Chengde Medical University, Chengde, Hebei 067000, China \\ ${ }^{2}$ Qingdao University Medical College, Qingdao, Shandong 266000, China \\ ${ }^{3}$ Yunnan Cancer hospital, Kunming, Yunnan 650000, China \\ Correspondence should be addressed to Youxin Song; syxmed@126.com
}

Received 8 July 2020; Revised 30 September 2020; Accepted 27 October 2020; Published 18 November 2020

Academic Editor: Baotong Zhang

Copyright ( 2020 Yuexin Tong et al. This is an open access article distributed under the Creative Commons Attribution License, which permits unrestricted use, distribution, and reproduction in any medium, provided the original work is properly cited.

\begin{abstract}
Brain metastasis (BM) is a typical type of metastasis in renal cell carcinoma (RCC) patients. The early detection of BM is likely a crucial step for RCC patients to receive appropriate treatment and prolong their overall survival. The aim of this study was to identify the independent predictors of $\mathrm{BM}$ and construct a nomogram to predict the risk of BM. Demographic and clinicopathological data were obtained from the Surveillance, Epidemiology, and End Results (SEER) database for RCC patients between 2010 and 2015. Univariate and multivariate logistic regression analyses were performed to identify the independent risk factors, and then, a visual nomogram was constructed. Multiple parameters were used to evaluate the discrimination and clinical value. We finally included 42577 RCC patients. Multivariate logistic regression analysis showed that histological type, tumor size, bone metastatic status, and lung metastatic status were independent BM-associated risk factors for RCC. We developed a nomogram to predict the risk of BM in patients with RCC, which showed favorable calibration with a $C$-index of 0.924 (0.903$0.945)$ in the training cohort and 0.911 (0.871-0.952) in the validation cohort. The calibration curves and decision curve analysis (DCA) also demonstrated the reliability and accuracy of the clinical prediction model. The nomogram was shown to be a practical, precise, and personalized clinical tool for identifying the RCC patients with a high risk of BM, which not only will contribute to the more reasonable allocation of medical resources but will also enable a further improvements in the prognosis and quality of life of RCC patients.
\end{abstract}

\section{Introduction}

Renal cell carcinoma (RCC) is a common malignancy of the genitourinary system [1], with over 400,000 new cases and 17,000 RCC-associated mortalities in 2018 worldwide [2]. Approximately one-quarter of patients with RCC have metastatic disease at the time of diagnosis, and another 35\% of them will develop distant metastases (DMs) during the process of tumor progression $[3,4]$. Brain metastasis (BM) is a typical type of metastasis in RCC patients. In a study conducted by Bianchi et al., it was shown that the rate of BM ranged from $2 \%$ to $16 \%$ in metastatic RCC (mRCC) [5]. Although noticeable progress has been made in tumor treat- ment during the last several decades, renal cell carcinoma with brain metastasis (RCCBM) exhibits a limited response to current anticancer treatment methods [6-8]. BM is still thought to be closely related to mortality for patients with advanced-stage RCC [9]. The median overall survival of RCC patients with BM has been described as only 5-8 months $[10,11]$. Thus, RCCBM is considered a significant issue in RCC studies.

The evaluation of BM in RCC may help improve clinical outcome and perhaps contribute to decreasing the potential risks of aggressive multimodality treatment required for advanced-stage cancer. Verma and his colleagues found that the use of tyrosine kinase inhibitors (TKIs) influenced the 
natural disease course and prognosis of RCC by preventing the development of BM [12]. Thus, the improved understanding and surveillance of BM will be beneficial for improving long-term prognosis for RCC patients. Some exploratory-stage predictors have been reported to evaluate the risks of BM in RCC. A retrospective study on 52 RCCBM patients revealed that smoking cigarettes and lung metastases were highly associated with the RCCBM [13]. However, no studies have focused on the development of an ideal predictive model for predicting the risk of BM in RCC, which means that the probability of BM cannot be quantified. In other words, the performance of BM-related factors in the prospective prediction of BM in RCC patients is still unknown. Due to the rarity of BM in RCC, obtaining adequate cases from our clinical practice to conduct the current study was extremely difficult. Thus, we used the Surveillance, Epidemiology, and End Results (SEER) database, a commonly used tool to study rare tumors, which provides data from 18 cancer registries and includes approximately $30 \%$ of the United States population. Therefore, the purpose of this study was to establish and validate a clinical prediction model to quantifying the risk of BM for RCC patients based on the SEER database. This study will help to promote personalized treatment and medical decision-making for patients with RCC.

\section{Materials and Methods}

2.1. Study Population Selection. The study population was derived from the SEER database, and the data were downloaded with $\mathrm{SEER} *$ Stat software version 8.3.6. The SEER program is an open access database which sponsored by the National Cancer Institute that contains demographic and clinicopathological information on cancer incidence and survival from 18 population-based cancer registries. The inclusion criteria were as follows: (1) patients with a histological diagnosis of RCC from 2010 to 2015 (histologic codes: $8310 / 3,8313 / 3,8260 / 3,8317 / 3,8270 / 3$, and 8319/3); (2) RCC was the first and only primary cancer; patients with important clinical information on age, race, sex, histological type, histological grade, laterality, $\mathrm{T}$ stage, $\mathrm{N}$ stage, tumor size, insurance status, marital status, and distant metastatic status (brain, lung, bone, and liver) were unknown and excluded from this study. Finally, a total of 42577 RCC patients were identified to evaluate risk factors for the development of BM in patients with RCC and construct a diagnostic nomogram. In addition, this study was exempt from a medical ethics review and did not require informed consent because the data extracted from the SEER database were anonymized and deidentified prior to release. Figure 1 shows the process of patients' selection procedure in this study.

2.2. Data Elements. Based on accessible demographic data and tumor clinicopathological data recorded in the SEER database and previous studies, we extracted 14 variables from the SEER database that could be potentially associated with the development of BM in RCC patients. Demographic variables included age, sex, race, insurance status, and marital status. Cancer characteristics included the tumor size, histo- logical grade, histological type, laterality, $\mathrm{T}$ stage, and $\mathrm{N}$ stage. In addition, we included data on metastases, including liver metastases (yes or no), lung metastases (yes or no), and bone metastases (yes or no). Histological type were defined by ICD-O-3 codes: clear cell $(8310 / 3,8313 / 3)$, papillary (8260/3), chromophobe $(8317 / 3,8270 / 3)$, and collecting duct $(8319 / 3)$. All patients in this study were staged using the American Joint Committee on Cancer TNM staging system, 7 th edition.

2.3. Statistical Analysis. R software (version 3.6.1) and SPSS 25.0 were used for all statistical analyses in this study. All patients were divided into training $(n=29805)$ and validation $(n=12772)$ cohorts with a ratio of $7: 3$. The classification process was completely randomized and performed with $\mathrm{R}$ software. The diagnostic nomogram was constructed based on patients in the training cohort and tested by patients in the validation cohort. Univariate logistic analysis was performed to identify BM-associated risk factors. Variables with a $P$ value $<0.05$ in univariate analysis were further incorporated into multivariate logistic regression analysis to identify the independent risk factors for BM in RCC patients. A multivariate logistic regression model was developed to quantify the relationship between BM and the potential characteristics that were meaningful in univariate analysis. The diagnostic nomogram was constructed with the "rms" package in $\mathrm{R}$ software based on the independent risk factors for $\mathrm{BM}$ in HCC patients. Meanwhile, a receiver operating characteristic (ROC) curve was plotted, and the area under the curve (AUC) was used to show the discrimination of the diagnostic nomogram. The AUCs of each independent risk factor were also compared with the AUC of the predictive nomogram. Moreover, a calibration curve was generated and decision curve analyses (DCA) were performed to evaluate the diagnostic nomogram. In the present study, a $P$ value $<0.05$ (two-sided) was considered statically significant.

\section{Results}

3.1. Baseline Characteristics. Between 2010 and 2015, a total of 42577 patients diagnosed with RCC were included in this study cohort, of whom 228 patients had BM. In the training cohort, the majority were White people in race distribution $(82.53 \%)$, and 19039 patients $(63.88 \%)$ were male. Most of RCC patients (97.35\%) received external economic support. As regards tumor characteristics, the most common $\mathrm{T}$ stage and N stage were T1-2 (79.60\%) and N0 (97.17\%), respectively. There was no significant difference in laterality, with left accounting for $49.38 \%$ and right accounting for $50.62 \%$ of RCC patients. The proportion of patients with clear cell RCC in this study was $79.01 \%$. The detailed baseline characteristics for all patients are shown in Table 1.

3.2. Risk Factors for BM in RCC Patients. To identify the BMassociated variables in RCC patients, 14 variables were analyzed. Different variables were classified according to whether the patient had BM or not. In the training cohort, univariate analysis identified race $(P=0.009)$, histological grade $(P<0.001)$, T stage $(P<0.001)$, histological type 


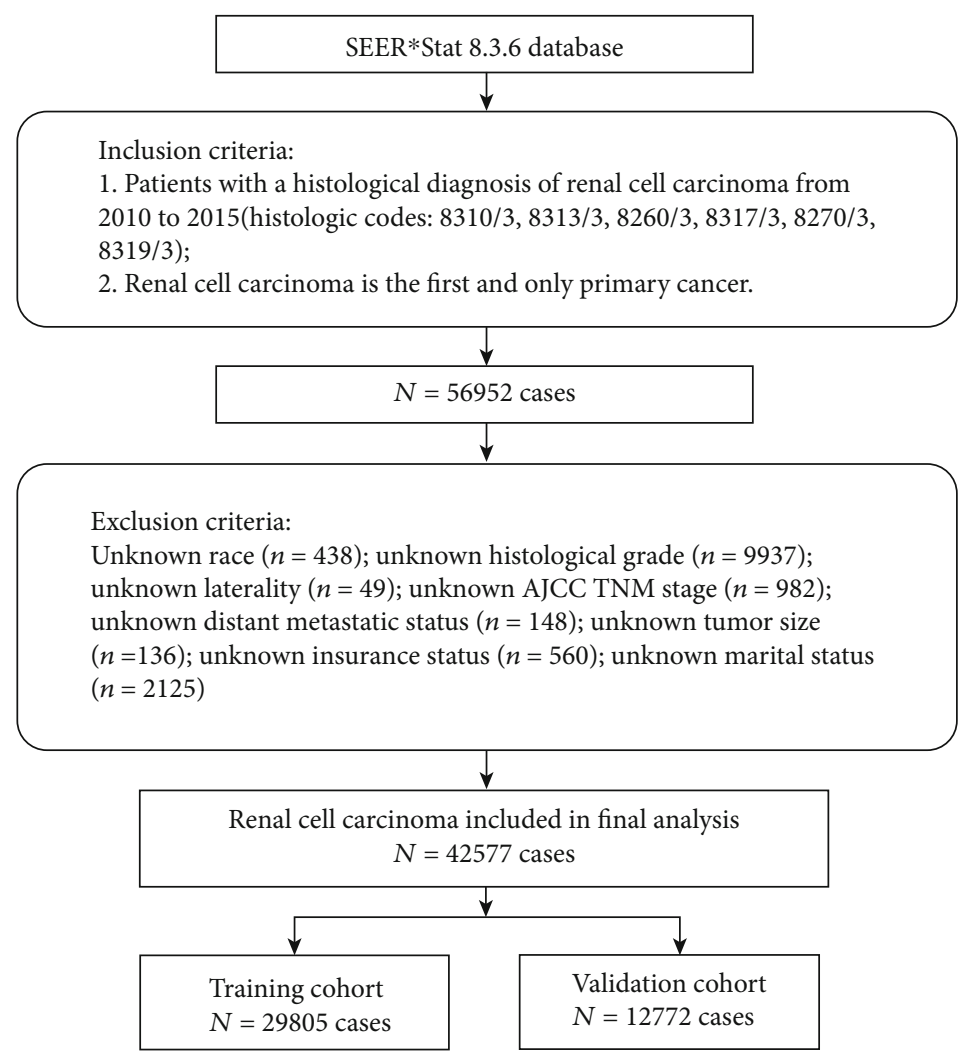

FIGURE 1: The diagram of the process of patient selection.

$(P<0.001)$, N stage $(P<0.001)$, bone metastasis $(P<0.001)$, liver metastasis $(P<0.001)$, lung metastasis $(P<0.001)$, and tumor size $(P<0.001)$. Subsequently, the above variables were further included in multivariate logistic regression analysis, which showed that histological type $(P=0.005)$, bone metastasis $(P<0.001)$, lung metastasis $(P<0.001)$, and tumor size $(P<0.001)$ were independent predictors for $\mathrm{BM}$ in RCC patients. Details are presented in Table 2.

3.3. Development and Validation of a Diagnostic Nomogram for BM in RCC Patients. Based on multivariate logistic regression analysis, a diagnostic nomogram was constructed to predict the risk of BM in RCC patients (Figure 2). In the diagnostic nomogram, values for individual patients are located along the variable axes, and a line is drawn upward to the point axis to determine the number of points assigned for each variable. There is a total point line at the bottom of the nomogram, and each variable score is summed to give the total points. Then, a vertical line is drawn from the total point scale to the BM axis to obtain the probability. To assess the accuracy and validity of the model, ROC curves are plotted in Figure 3, with AUC in the training and validation cohorts of 0.924 (0.903-0.945) and 0.911 (0.871-0.952), respectively, indicating that the risk model has a better discriminative ability. The calibration curve showed high consistency between the observed and predicted results (Figure 4). In addition, the DCA results suggested that the nomogram was a good diagnostic tool for the risk of developing $\mathrm{BM}$ in patients with RCC (Figure 5). Moreover, as shown in Figure 6, ROC curves of each independent BM-associated risk factor were also generated in this study. The results showed that the AUC of the comprehensive nomogram was higher than the AUC of any single independent predictor.

\section{Discussion}

In recent decades, considerable advances in tumor therapy have significantly improved the overall survival of mRCC patients $[14,15]$. BM in RCC is still an important topic in the field of kidney malignancy research. Although the occurrence of BM is relatively low, it was reported that the presence of BM signified a worse prognosis compared with the lung or bone metastases [16]. A recent retrospective study suggested that the median overall survival of RCCBM patients was only 8.2 months [17]. However, the early detection of BM is likely a crucial step for RCC patients to receive appropriate treatment and prolong their overall survival. Nevertheless, brain imaging is not routinely recommended for all RCC patients based on surveillance guidelines from the American Urologic Association, European Association of Urology, and National Comprehensive Cancer Network, unless clinical or laboratory evidence indicates a high risk of BM for individual patients [18-20].

It therefore seems significant for clinical decision-making and personalized management to explore BM-related predictors in RCC patients and identify RCC patients with a high risk of BM. A conventional study reported that tumor size and age were risk factors for BM in RCC [21]. However, to date, a convenient predictive model for predicting $\mathrm{BM}$ in RCC has not been developed, which means that the personal 
TABLE 1: Demographics and clinical characteristics of RCC patients.

\begin{tabular}{|c|c|c|c|c|}
\hline \multirow{2}{*}{ Variables } & \multicolumn{2}{|c|}{$\begin{array}{l}\text { Training cohort } \\
(N=29805)\end{array}$} & \multicolumn{2}{|c|}{$\begin{array}{l}\text { Validation cohort } \\
\quad(N=12772)\end{array}$} \\
\hline & $\begin{array}{l}\text { Without BM } \\
(N=29652)\end{array}$ & $\begin{array}{l}\text { With BM } \\
(N=153)\end{array}$ & $\begin{array}{l}\text { Without BM } \\
(N=12697)\end{array}$ & $\begin{array}{l}\text { With BM } \\
(N=75)\end{array}$ \\
\hline \multicolumn{5}{|c|}{ Age (years) } \\
\hline$<45$ & $2943(9.2 \%)$ & $11(7.2 \%)$ & $1238(9.8 \%)$ & $3(4.0 \%)$ \\
\hline $45-65$ & $\begin{array}{c}15279 \\
(51.5 \%)\end{array}$ & $\begin{array}{c}92 \\
(60.1 \%)\end{array}$ & $6553(51.6 \%)$ & $\begin{array}{c}50 \\
(66.7 \%)\end{array}$ \\
\hline$>65$ & $\begin{array}{c}11430 \\
(38.5 \%)\end{array}$ & $\begin{array}{c}50 \\
(32.7 \%)\end{array}$ & $4906(38.6 \%)$ & $\begin{array}{c}22 \\
(29.3 \%)\end{array}$ \\
\hline \multicolumn{5}{|l|}{ Race } \\
\hline Black & $3258(10.9 \%)$ & $7(4.6 \%)$ & $1430(11.3 \%)$ & $1(1.3 \%)$ \\
\hline Other $^{a}$ & $1929(6.5 \%)$ & $14(9.2 \%)$ & $835(6.6 \%)$ & $8(10.7 \%)$ \\
\hline White & $\begin{array}{c}24465 \\
(82.5 \%)\end{array}$ & $\begin{array}{c}132 \\
(86.2 \%)\end{array}$ & $\begin{array}{c}10432 \\
(82.1 \%)\end{array}$ & $\begin{array}{c}66 \\
(88.0 \%)\end{array}$ \\
\hline \multicolumn{5}{|l|}{ Sex } \\
\hline Female & $\begin{array}{c}10721 \\
(36.2 \%)\end{array}$ & $\begin{array}{c}45 \\
(29.4 \%)\end{array}$ & $4556(35.9 \%)$ & $\begin{array}{c}21 \\
(28.0 \%)\end{array}$ \\
\hline Male & $\begin{array}{c}18931 \\
(63.8 \%)\end{array}$ & $\begin{array}{c}108 \\
(70.6 \%)\end{array}$ & $8141(64.1 \%)$ & $\begin{array}{c}54 \\
(72.0 \%)\end{array}$ \\
\hline \multicolumn{5}{|c|}{ Histological type } \\
\hline $\mathrm{pRCC}$ & $4637(15.6 \%)$ & $3(2.0 \%)$ & 2025 (15.9\%) & $2(2.7 \%)$ \\
\hline cRCC & $1548(5.2 \%)$ & $2(1.3 \%)$ & $652(5.1 \%)$ & $0(0.0 \%)$ \\
\hline ccRCC & $\begin{array}{c}23403 \\
(78.9 \%)\end{array}$ & $\begin{array}{c}147 \\
(96.0 \%)\end{array}$ & 9989 (78.7\%) & $\begin{array}{c}72 \\
(96.0 \%)\end{array}$ \\
\hline $\operatorname{cdRCC}$ & $64(0.2 \%)$ & $1(0.7 \%)$ & $31(0.2 \%)$ & $1(1.3 \%)$ \\
\hline \multicolumn{5}{|c|}{ Histological grade } \\
\hline Grade I & $3416(11.5 \%)$ & $6(4.0 \%)$ & $1392(11.0 \%)$ & $1(1.3 \%)$ \\
\hline Grade II & $\begin{array}{c}15651 \\
(52.8 \%)\end{array}$ & $\begin{array}{c}41 \\
(26.8 \%)\end{array}$ & $6931(54.6 \%)$ & $\begin{array}{c}21 \\
(28.0 \%)\end{array}$ \\
\hline Grade III & $8757(29.5 \%)$ & $\begin{array}{c}64 \\
(41.8 \%)\end{array}$ & $3622(28.5 \%)$ & $\begin{array}{c}37 \\
(49.4 \%)\end{array}$ \\
\hline Grade IV & $1828(6.2 \%)$ & $\begin{array}{c}42 \\
(27.4 \%)\end{array}$ & $752(5.9 \%)$ & $\begin{array}{c}16 \\
(21.3 \%)\end{array}$ \\
\hline \multicolumn{5}{|l|}{ Laterality } \\
\hline Left & $\begin{array}{c}14638 \\
(49.4 \%)\end{array}$ & $\begin{array}{c}79 \\
(51.6 \%)\end{array}$ & $6205(48.9 \%)$ & $\begin{array}{c}40 \\
(53.3 \%)\end{array}$ \\
\hline Right & $\begin{array}{c}15014 \\
(50.6 \%)\end{array}$ & $\begin{array}{c}74 \\
(48.4 \%)\end{array}$ & $6492(51.1 \%)$ & $\begin{array}{c}35 \\
(46.7 \%)\end{array}$ \\
\hline \multicolumn{5}{|l|}{ T stage } \\
\hline T1-2 & $\begin{array}{c}23661 \\
(79.8 \%)\end{array}$ & $\begin{array}{c}65 \\
(42.5 \%)\end{array}$ & $\begin{array}{c}10144 \\
(79.9 \%)\end{array}$ & $\begin{array}{c}31 \\
(41.3 \%)\end{array}$ \\
\hline T3-4 & $5591(18.9 \%)$ & $\begin{array}{c}88 \\
(57.5 \%)\end{array}$ & $2553(20.1 \%)$ & $\begin{array}{c}44 \\
(58.7 \%)\end{array}$ \\
\hline \multicolumn{5}{|l|}{$N$ stage } \\
\hline N0 & $\begin{array}{c}28843 \\
(97.3 \%)\end{array}$ & $\begin{array}{c}119 \\
(77.8 \%)\end{array}$ & $\begin{array}{c}12348 \\
(97.3 \%)\end{array}$ & $\begin{array}{c}61 \\
(81.3 \%)\end{array}$ \\
\hline N1-2 & $809(2.7 \%)$ & $\begin{array}{c}34 \\
(22.2 \%)\end{array}$ & $349(2.7 \%)$ & $\begin{array}{c}14 \\
(18.7 \%)\end{array}$ \\
\hline \multicolumn{5}{|c|}{ Bone metastasis } \\
\hline No & $\begin{array}{c}29171 \\
(98.4 \%)\end{array}$ & $\begin{array}{c}111 \\
(72.5 \%)\end{array}$ & $\begin{array}{c}12505 \\
(98.5 \%)\end{array}$ & $\begin{array}{c}49 \\
(65.3 \%)\end{array}$ \\
\hline Yes & $481(1.6 \%)$ & & $192(1.5 \%)$ & \\
\hline
\end{tabular}

TABle 1: Continued.

\begin{tabular}{|c|c|c|c|c|}
\hline \multirow{2}{*}{ Variables } & \multicolumn{2}{|c|}{$\begin{array}{l}\text { Training cohort } \\
\quad(N=29805)\end{array}$} & \multicolumn{2}{|c|}{$\begin{array}{l}\text { Validation cohort } \\
\quad(N=12772)\end{array}$} \\
\hline & $\begin{array}{l}\text { Without BM } \\
(N=29652)\end{array}$ & $\begin{array}{l}\text { With BM } \\
(N=153)\end{array}$ & $\begin{array}{l}\text { Without BM } \\
(N=12697)\end{array}$ & $\begin{array}{l}\text { With BM } \\
(N=75)\end{array}$ \\
\hline & & $\begin{array}{c}42 \\
(27.5 \%)\end{array}$ & & $\begin{array}{c}26 \\
(34.7 \%)\end{array}$ \\
\hline \multicolumn{5}{|c|}{ Liver metastasis } \\
\hline No & $\begin{array}{c}29472 \\
(99.4 \%)\end{array}$ & $\begin{array}{c}138 \\
(90.2 \%)\end{array}$ & $\begin{array}{c}12620 \\
(99.4 \%)\end{array}$ & $\begin{array}{c}69 \\
(92.0 \%)\end{array}$ \\
\hline Yes & $180(0.6 \%)$ & $15(9.8 \%)$ & $77(0.6 \%)$ & $6(8.0 \%)$ \\
\hline \multicolumn{5}{|c|}{ Lung metastasis } \\
\hline No & $\begin{array}{c}28719 \\
(96.9 \%)\end{array}$ & $\begin{array}{c}55 \\
(35.9 \%)\end{array}$ & $\begin{array}{c}12300 \\
(96.9 \%)\end{array}$ & $\begin{array}{c}23 \\
(30.7 \%)\end{array}$ \\
\hline Yes & $933(3.1 \%)$ & $\begin{array}{c}98 \\
(64.1 \%)\end{array}$ & $397(3.1 \%)$ & $\begin{array}{c}52 \\
(69.3 \%)\end{array}$ \\
\hline
\end{tabular}

Tumor size

$\begin{array}{lcccc}\leq 4 \mathrm{~cm} & 13608 & 5(3.3 \%) & 6289(49.5 \%) & 8(10.7 \%) \\ & (45.9 \%) & & & \\ 4-7 \mathrm{~cm} & 9269(31.3 \%) & 23 & 3778(29.8 \%) & 17 \\ & & (15.0 \%) & & (22.7 \%) \\ 7-10 \mathrm{~cm} & 4069(13.7 \%) & 60 & 1603(12.6 \%) & 25 \\ & & (39.2 \%) & (33.3 \%) \\ >10 & 2706(9.1 \%) & 65 & 1027(8.1 \%) & 25 \\ & & (42.5 \%) & & (33.3 \%)\end{array}$

Insurance status

$\begin{array}{lcccc} & 28868 & 148 & 12390 & 72 \\ \text { Insured }^{\mathrm{b}} & (97.4 \%) & (96.7 \%) & (97.6 \%) & (96.0 \%) \\ \text { Uninsured } & 784(2.6 \%) & 5(3.3 \%) & 307(2.4 \%) & 3(4.0 \%)\end{array}$

Marital status

\begin{tabular}{lcccc} 
Married & 19206 & 92 & $8335(65.6 \%)$ & 58 \\
& $(64.8 \%)$ & $(60.1 \%)$ & & $(77.3 \%)$ \\
Unmarried $^{c}$ & 10446 & 61 & $4362(34.4 \%)$ & 17 \\
& $(35.2 \%)$ & $(39.9 \%)$ & & $(22.7 \%)$ \\
\hline
\end{tabular}

${ }^{a}$ American Indian, native Alaskan and Asian, and Pacific Islander. ${ }^{\mathrm{b}}$ Any medicaid, insured, and insured/not specific. ' Unmarried, separated, single, widow, and divorced. pRCC: papillary renal cell carcinoma; cRCC: chromophobe renal cell carcinoma; ccRCC: clear cell renal cell carcinoma; cdRCC: collecting duct renal cell carcinoma.

risk of $\mathrm{BM}$ cannot be accurately estimated by combining all independent risk factors for BM. Nomograms are an easyto-understand and multivariate visualization model to predict and quantify the incidence of a specific clinical outcome for individual patients and are widely applied in various malignancies [22-24]. Each independent risk factor included in the model was given a weighted point value to represent its effect on BM in RCC. This tool could be used to provide a reference for scientific and rational clinical decisions and promote the development of precision cancer medicine.

In our study, the analysis based on the SEER database from 2010 to 2015 indicated that histological type, tumor size, bone metastatic status, and lung metastatic status were independent risk factors for BM in RCC. There might be a relationship between histological grade, race, $\mathrm{T}$ stage, $\mathrm{N}$ stage, liver metastasis status, and $\mathrm{BM}$, while these variables did not show a statistically significant association with BM 
TABLE 2: Logistic regression analysis of independent risk factors of BM in RCC patients.

\begin{tabular}{|c|c|c|c|c|}
\hline \multirow{2}{*}{ Variable } & \multicolumn{2}{|c|}{ Univariate analysis } & \multicolumn{2}{|c|}{ Multivariate analysis } \\
\hline & OR $(95 \% \mathrm{CI})$ & $P$ value & OR $(95 \% \mathrm{CI})$ & $P$ value \\
\hline \multicolumn{5}{|c|}{ Age (years) } \\
\hline$<45$ & Reference & & & \\
\hline $45-65$ & $1.611(0.861-3.014)$ & 0.136 & & \\
\hline$>65$ & $1.170(0.609-2.251)$ & 0.637 & & \\
\hline \multicolumn{5}{|l|}{ Race } \\
\hline Black & Reference & & & \\
\hline Other $^{\mathrm{a}}$ & $3.378(1.361-8.384)$ & 0.009 & & \\
\hline White & $2.511(1.173-5.375)$ & 0.018 & & \\
\hline \multicolumn{5}{|l|}{ Sex } \\
\hline Female & Reference & & & \\
\hline Male & $1.359(0.959-1.926)$ & 0.084 & & \\
\hline \multicolumn{5}{|c|}{ Histological type } \\
\hline pRCC & Reference & & & \\
\hline cRCC & $1.997(0.333-11.962)$ & 0.449 & $1.958(0.321-11.938)$ & 0.467 \\
\hline ccRCC & $9.709(3.094-30.464)$ & $<0.001$ & $5.239(1.650-16.638)$ & 0.005 \\
\hline cdRCC & $24.151(2.479-235.310)$ & 0.006 & $3.523(0.336-36.896)$ & 0.293 \\
\hline \multicolumn{5}{|c|}{ Histological grade } \\
\hline Grade I & Reference & & & \\
\hline Grade II & $1.491(0.633-3.516)$ & 0.361 & & \\
\hline Grade III & $4.161(1.800-9.617)$ & 0.001 & & \\
\hline Grade IV & $13.081(5.550-30.829)$ & $<0.001$ & & \\
\hline \multicolumn{5}{|l|}{ Laterality } \\
\hline Left & Reference & & & \\
\hline Right & $0.913(0.665-1.255)$ & 0.576 & & \\
\hline \multicolumn{5}{|l|}{ T stage } \\
\hline $\mathrm{T} 1-2$ & Reference & & & \\
\hline T3-4 & $5.347(3.876-7.377)$ & $<0.001$ & & \\
\hline \multicolumn{5}{|l|}{$N$ stage } \\
\hline No & Reference & & & \\
\hline N1-2 & $10.186(6.914-15.007)$ & $<0.001$ & & \\
\hline \multicolumn{5}{|c|}{ Bone metastasis } \\
\hline No & Reference & & & \\
\hline Yes & $22.947(15.909-33.100)$ & $<0.001$ & $2.924(1.937-4.416)$ & $<0.001$ \\
\hline \multicolumn{5}{|c|}{ Liver metastasis } \\
\hline No & Reference & & & \\
\hline Yes & $17.797(10.241-30.928)$ & $<0.001$ & & \\
\hline \multicolumn{5}{|c|}{ Lung metastasis } \\
\hline No & Reference & & & \\
\hline Yes & $54.847(39.172-76.795)$ & $<0.001$ & $15.649(10.529-23.259)$ & $<0.001$ \\
\hline \multicolumn{5}{|c|}{ Tumor size } \\
\hline$\leq 4 \mathrm{~cm}$ & Reference & & & \\
\hline $4-7 \mathrm{~cm}$ & $6.753(2.567-17.770)$ & $<0.001$ & $4.971(1.880-13.146)$ & 0.001 \\
\hline $7-10 \mathrm{~cm}$ & $40.132(16.106-99.998)$ & $<0.001$ & $14.997(5.865-38.346)$ & $<0.001$ \\
\hline$>10$ & $65.375(26.301-162.501)$ & $<0.001$ & $14.620(5.631-37.962)$ & $<0.001$ \\
\hline
\end{tabular}


TABLE 2: Continued.

\begin{tabular}{|c|c|c|c|c|}
\hline \multirow{2}{*}{ Variable } & \multicolumn{2}{|c|}{ Univariate analysis } & \multicolumn{2}{|c|}{ Multivariate analysis } \\
\hline & OR $(95 \% \mathrm{CI})$ & $P$ value & OR (95\% CI) & $P$ value \\
\hline \multicolumn{5}{|c|}{ Insurance status } \\
\hline Insured $^{\mathrm{b}}$ & Reference & & & \\
\hline Uninsured & $1.244(0.509-3.041)$ & 0.632 & & \\
\hline \multicolumn{5}{|c|}{ Marital status } \\
\hline Married & Reference & & & \\
\hline Unmarried $^{c}$ & $1.219(0.881-1.686)$ & 0.32 & & \\
\hline
\end{tabular}

${ }^{a}$ American Indian, native Alaskan and Asian, and Pacific Islander. ${ }^{b}$ Any medicaid, insured, and insured/not specific. ${ }^{c}$ Unmarried, separated, single, widow, and divorced. pRCC: papillary renal cell carcinoma; cRCC: chromophobe renal cell carcinoma; ccRCC: clear cell renal cell carcinoma; cdRCC: collecting duct renal cell carcinoma.

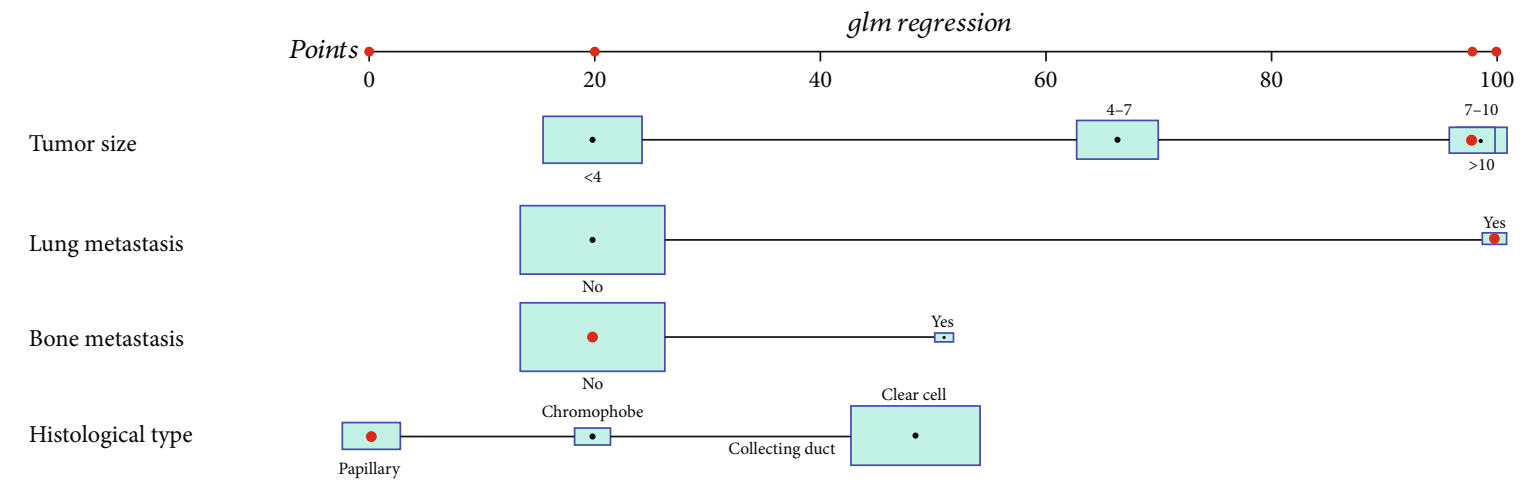

Total-points-to-outcome nomogram:

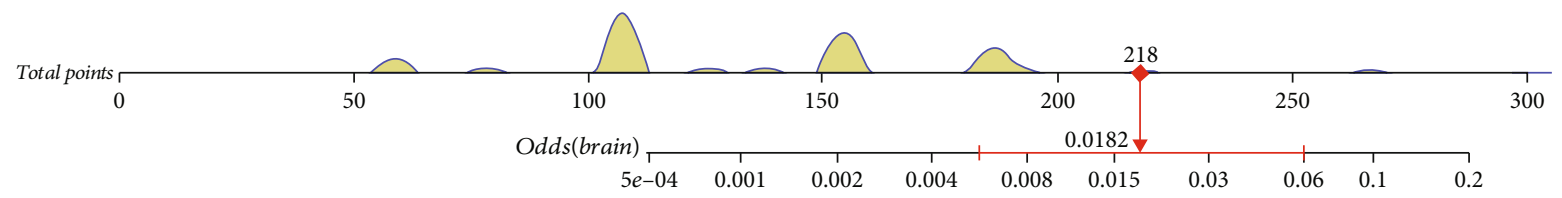

FIGURE 2: A nomogram prediction model for risk of BM in patients with RCC.

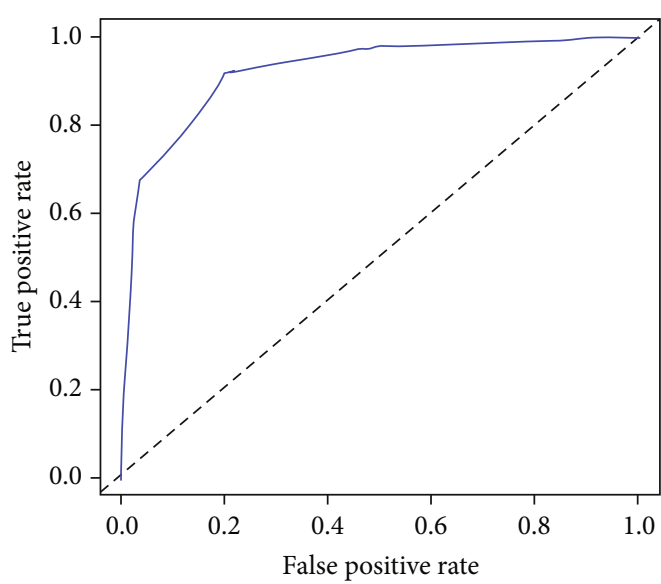

(a)

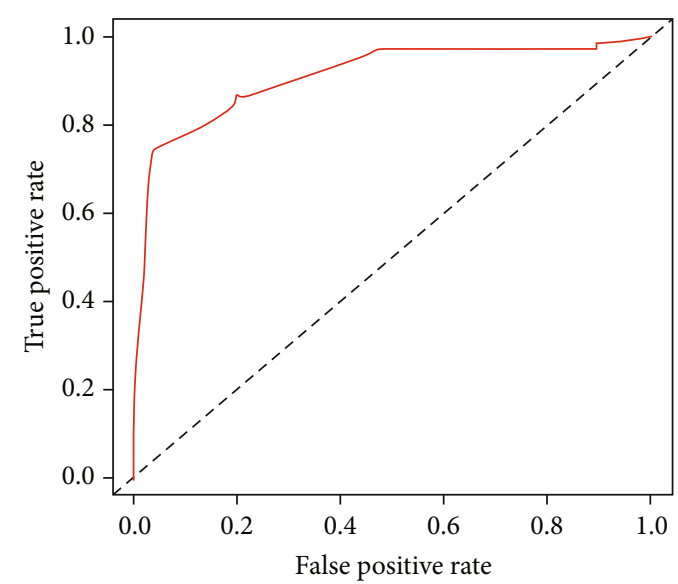

(b)

FIGURE 3: Receiver operating characteristic (ROC) curves and area under curve (AUC) of the nomogram for predicting BM in patients with $\mathrm{RCC}$ in the training cohort (a) and the validation cohort (b). The AUC was used to show the discrimination of the nomogram.

in the multivariate analysis. A visual nomogram was thus developed to predict the probability of BM in RCC. The established nomogram had high accuracy and sensitivity in terms of identifying BM in RCC, and its calibration curves also showed good concordance between predicted and observed BM probabilities. Clear cell RCC (ccRCC) patients 


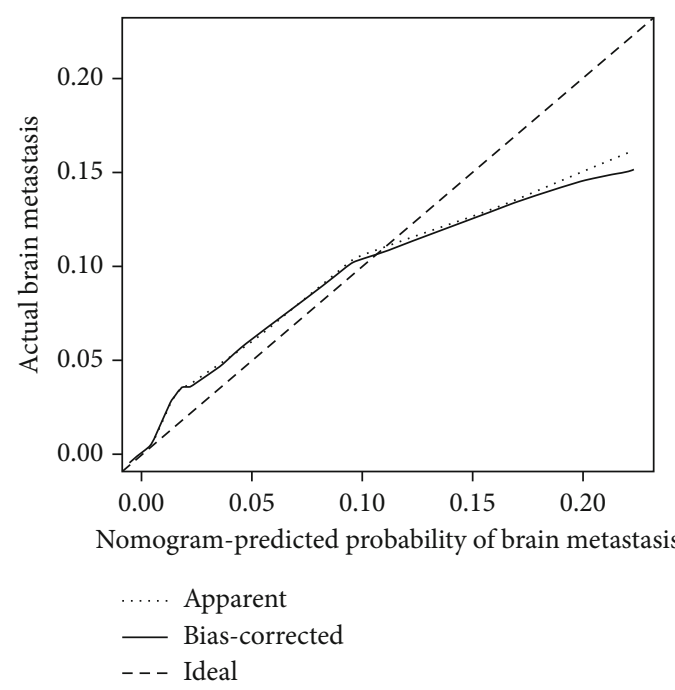

(a)

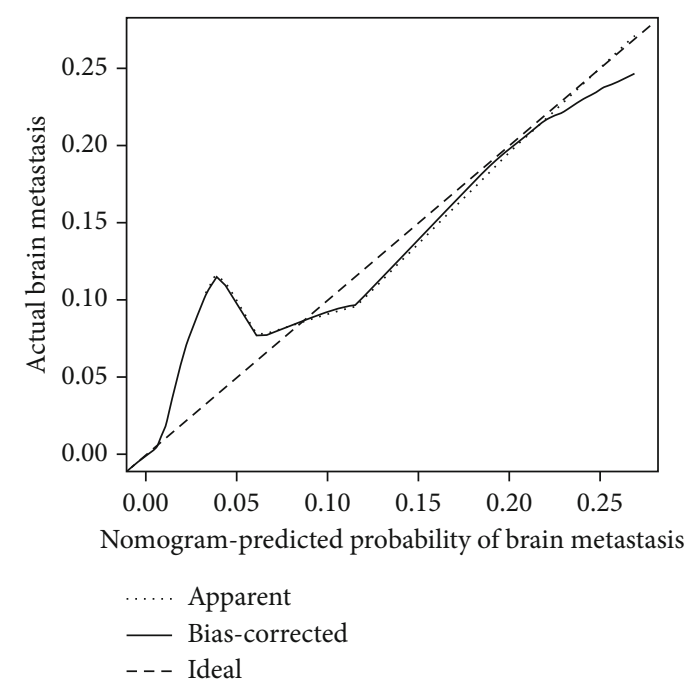

(b)

FIgURE 4: Calibration curves of the nomogram for predicting BM in patients with RCC in the training cohort (a) and the validation cohort (b). The $x$-axis represents the nomogram-predicted probability of BM; the $y$-axis represents the actual probability of BM. Plots along the 45 degree line indicate a perfect calibration model in which the predicted probabilities are identical to the actual outcomes.

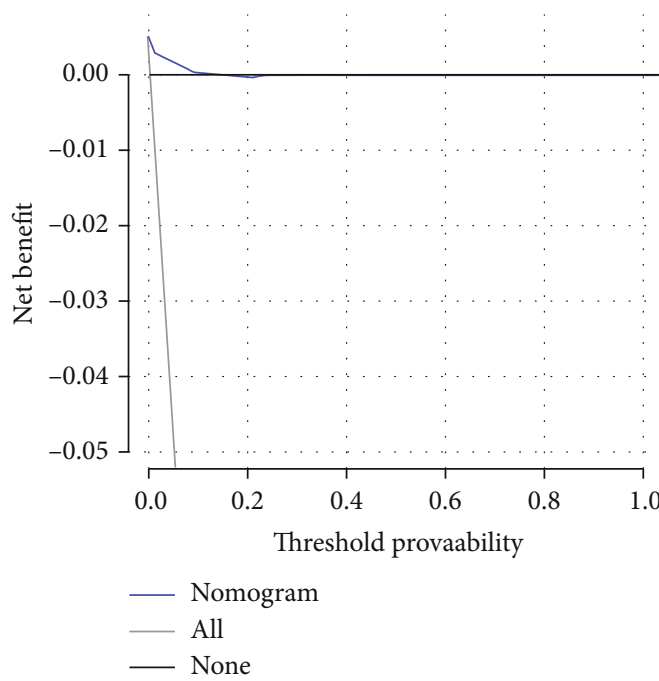

(a)

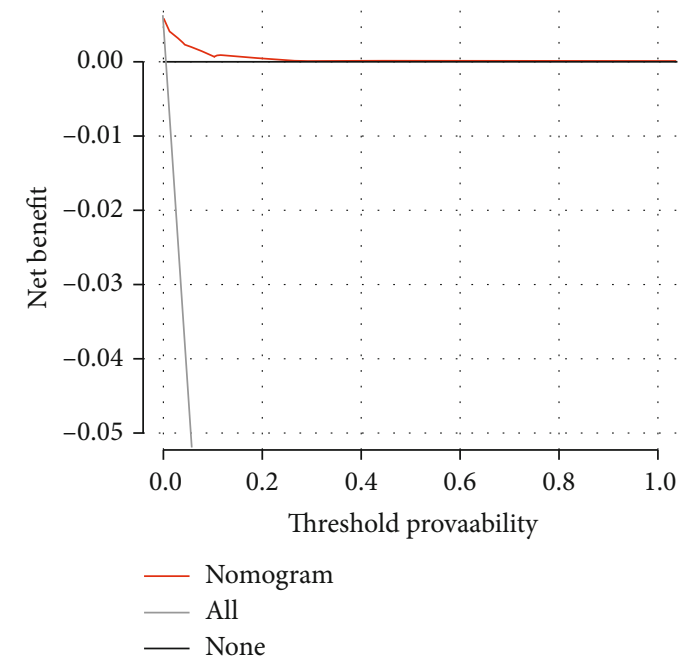

(b)

FIgURE 5: Decision curve analysis (DCA) of the nomogram for predicting BM in patients with RCC in the training cohort (a) and the validation cohort (b). This diagnostic nomogram shows a notable positive net benefit, indicating that it has a good clinical utility in predicting estimating the risk of BM in patients with RCC.

with a tumor size $\geq 7 \mathrm{~cm}$ and bone and lung metastasis have higher a risk of BM. Even though in the absence of concerning neurological symptoms, including headache, dizziness, and altered consciousness, targeted brain imaging should be performed for RCC patients with a high risk of BM during a clinical follow-up. Generally, biological characteristics of the tumor play a crucial role in disease progression and are thought to be closely correlated with metastasis formation [25]. In a previous study, tumor size was proven to be a significant factor in the progression of distant metastasis for
RCC patients, and there was a linear positive correlation between tumor size and the metastatic rate [26]. This observation was also confirmed in our study. RCC patients with larger tumor diameters $(>7 \mathrm{~cm})$ showed a higher risk of BM in multivariate analysis. In a retrospective series focused on patients with metastatic RCC in the brain, Shuch et al. suggested that clear cell RCC appeared to be the predominant histological type that metastasized to the brain, and this type accounted for $92.7 \%$ of RCC patients with BM [27]. SuarezSarmiento et al. also found that clear cell RCC patients were 


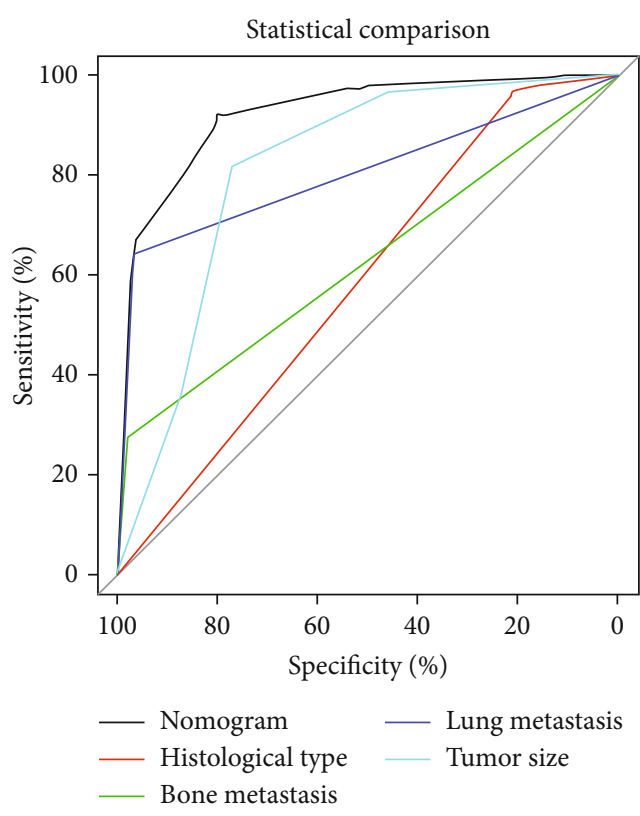

(a)

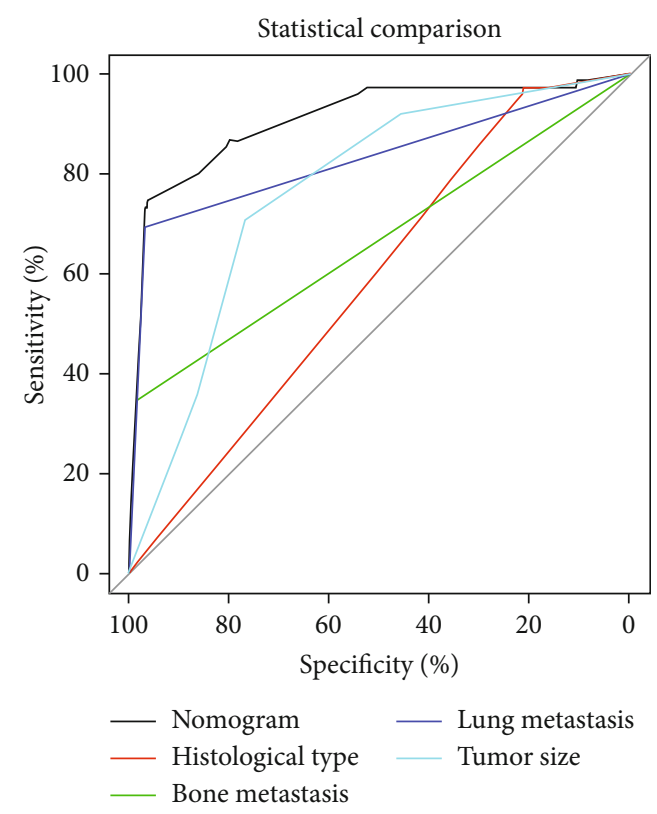

(b)

FIGURE 6: Comparison of AUC between the predictive nomogram and each independent predictor in the training cohort (a) and the validation cohort (b).

prone to developing BM [28]. Our study also identified histological type as an independent BM-related risk factor for RCC patients, which was similar to previous observations. Furthermore, in 2011, Verma et al. reported that lung metastasis was associated with a significantly high risk of developing BM in RCC patients [12]. Among 44 RCCBM patients, almost $90 \%$ had lung metastasis at diagnosis, and only $2.5 \%$ of RCC patients without lung metastasis ultimately developed BM. Therefore, it is worth investigating whether other extracranial metastases promote the development of BM in a synergistic manner. Our study also found that lung and bone metastatic status were the independent risk factors for BM in RCC patients. Although we found that RCC patients with lung or bone metastasis face a higher risk of $\mathrm{BM}$, the complex mechanism remains unclear.

To the best of our knowledge, this is the first report on the construction of a practical nomogram for accurately predicting the probability of BM in RCC. Our comprehensive nomogram could be used as a supportive graphic tool to identify RCC patients with a considerably high propensity for BM, which not only will contribute to the more reasonable allocation of medical resources but will also enable further improvements in the prognosis and quality of life of RCC patients. The established nomogram demonstrated high accuracy and sensitivity for identifying BM in RCC, and its calibration curves also showed good concordance between predicted and observed BM probabilities. Even more notably, the ROC analysis in our study confirmed that the discriminative power of the nomogram was better than that of any the independent risk factors, again illustrating the significance of a comprehensive predictive model (Figure 5). In addition, the identified independent BM-related factors in our study are easily accessible in the daily clinic.
However, there were also some limitations of this study that should be mentioned. First, some selection bias was inevitable due to the retrospective design of our study. Second, we could not evaluate patients who developed BM after being diagnosed with RCC and during the disease course because detailed follow-up data about BM were not recorded in the SEER database. Third, the nomogram provided a relative reference for clinical doctors. In addition to the independent variables included in the nomogram, several other potentially significant details were missing in the current study, such as some laboratory data, molecular biological information of tumors, and clinical symptoms. Fourth, although it highlighted several of the most common metastatic sites of RCC patients, it did not provide data regarding other important types of metastases, such as adrenal metastases. The severity of metastases to other organs could not be obtained from the SEER database.

\section{Conclusion}

The present study identified tumor size, histological type, bone metastatic status, and lung metastatic status as independent risk factors of BM in RCC patients. These independent $\mathrm{BM}$-associated risk factors were integrated to build a diagnostic nomogram to identify RCC patients with a high risk of BM.

\section{Abbreviations}

RCC: Renal cell carcinoma

BM: Brain metastasis

mRCC: Metastatic renal cell carcinoma

SEER: Surveillance, Epidemiology, and End Results 
ROC: Receiver operating characteristic

DCA: Decision curve analysis

AUC: Area under the curve.

\section{Data Availability}

The datasets generated during and/or analyzed during the current study are available from the corresponding author on reasonable request.

\section{Conflicts of Interest}

The authors declare that they have no known competing financial interests or personal relationships which could have appeared to influence the work reported in this paper.

\section{Authors' Contributions}

Yuexin Tong and Youxin Song conceived and designed the study. Yuexin Tong, Changxing Chi, and Zhangheng Huang collected the clinical data and literature review. Chuan $\mathrm{Hu}$ conducted the statistical analysis and generated the figures and tables. Yuexin Tong wrote the manuscript. Yuexin Tong and Youxin Song revised the manuscript. Youxin Song supervised the research. All authors critically read the manuscript to improve intellectual content. All authors read and approved the final manuscript. Yuexin Tong, Zhangheng Huang, and Chuan Hu contributed equally to this work.

\section{Acknowledgments}

We are thankful for the contribution of the SEER database and the 18 registries supplying cancer research information and thank all colleagues and staff involved in the study for their contributions.

\section{References}

[1] R. L. Siegel, K. D. Miller, and A. Jemal, "Cancer statistics, 2020," CA: A Cancer Journal for Clinicians, vol. 70, no. 1, pp. 7-30, 2020.

[2] F. Bray, J. Ferlay, I. Soerjomataram, R. L. Siegel, L. A. Torre, and A. Jemal, "Global cancer statistics 2018: GLOBOCAN estimates of incidence and mortality worldwide for 36 cancers in 185 countries," CA: A Cancer Journal for Clinicians, vol. 68, no. 6, pp. 394-424, 2018.

[3] A. Rodriguez-Vida, T. E. Hutson, J. Bellmunt, and M. H. Strijbos, "New treatment options for metastatic renal cell carcinoma," ESMO Open, vol. 2, no. 2, article e000185, 2017.

[4] K. Gupta, J. D. Miller, J. Z. Li, M. W. Russell, and C. Charbonneau, "Epidemiologic and socioeconomic burden of metastatic renal cell carcinoma (mRCC): a literature review," Cancer Treatment Reviews, vol. 34, no. 3, pp. 193-205, 2008.

[5] M. Bianchi, M. Sun, C. Jeldres et al., "Distribution of metastatic sites in renal cell carcinoma: a population-based analysis," Annals of Oncology, vol. 23, no. 4, pp. 973-980, 2012.

[6] J. Hu, W. Guan, P. Liu et al., "Endoglin is essential for the maintenance of self-renewal and chemoresistance in renal cancer stem cells," Stem Cell Reports, vol. 9, no. 2, pp. 464-477, 2017.
[7] A. Parmar, B. Sander, G. A. Bjarnason, and K. K. W. Chan, "Systemic therapy in metastatic renal cell carcinoma: emerging challenges in therapeutic choice," Critical Reviews in Oncology/Hematology, vol. 152, article 102971, 2020.

[8] M. Tenold, P. Ravi, M. Kumar et al., "Current approaches to the treatment of advanced or metastatic renal cell carcinoma," American Society of Clinical Oncology educational book. American Society of Clinical Oncology. Annual Meeting, vol. 40, pp. 1-10, 2020.

[9] R. Soffietti, P. Cornu, J. Y. Delattre et al., "EFNS guidelines on diagnosis and treatment of brain metastases: report of an EFNS task force," European Journal of Neurology, vol. 13, no. 7, pp. 674-681, 2006.

[10] I. A. Bowman, A. Bent, T. le et al., "Improved survival outcomes for kidney cancer patients with brain metastases," Clinical Genitourinary Cancer, vol. 17, no. 2, pp. e263e272, 2019.

[11] W. Zhuang, Y. Li, P. Chen, J. Wang, W. Liu, and J. Chen, "Do renal cell carcinoma patients with brain metastases still need nephrectomy?," International Urology and Nephrology, vol. 51, no. 6, pp. 941-949, 2019.

[12] J. Verma, E. Jonasch, P. Allen, N. Tannir, and A. Mahajan, "Impact of tyrosine kinase inhibitors on the incidence of brain metastasis in metastatic renal cell carcinoma," Cancer, vol. 117, no. 21, pp. 4958-4965, 2011.

[13] M. Hanzly, D. Abbotoy, T. Creighton et al., "Early identification of asymptomatic brain metastases from renal cell carcinoma," Clinical \& Experimental Metastasis, vol. 32, no. 8, pp. 783-788, 2015.

[14] A. Schmidt, A. Azad, J. Goh et al., "Treatment selection for first-line metastatic renal cell carcinoma in Australia: impact of new therapy options," Asia-Pacific Journal of Clinical Oncology, vol. 15, Supplement 10, pp. 3-10, 2019.

[15] E. Jonasch, "NCCN Guidelines updates: management of metastatic kidney cancer," Journal of the National Comprehensive Cancer Network, vol. 17, no. 5.5, pp. 587-589, 2019.

[16] T. Chandrasekar, Z. Klaassen, H. Goldberg, G. S. Kulkarni, R. J. Hamilton, and N. E. Fleshner, "Metastatic renal cell carcinoma: patterns and predictors of metastases-A contemporary population-based series," Urologic Oncology: Seminars and Original Investigations, vol. 35, no. 11, pp. 661.e7-661.e14, 2017.

[17] N. Takeshita, M. Otsuka, T. Kamasako et al., "Prognostic factors and survival in Japanese patients with brain metastasis from renal cell cancer," International Journal of Clinical Oncology, vol. 24, no. 10, pp. 1231-1237, 2019.

[18] B. Ljungberg, K. Bensalah, S. Canfield et al., "EAU guidelines on renal cell carcinoma: 2014 update," European Urology, vol. 67, no. 5, pp. 913-924, 2015.

[19] S. M. Donat, M. Diaz, J. T. Bishoff et al., "Follow-up for clinically localized renal neoplasms: AUA Guideline," The Journal of Urology, vol. 190, no. 2, pp. 407-416, 2013.

[20] R. J. Motzer, E. Jonasch, N. Agarwal et al., "Kidney cancer, version 2.2014," Journal of the National Comprehensive Cancer Network: JNCCN, vol. 12, no. 2, pp. 175-182, 2014.

[21] Z. B. Ke, S. H. Chen, Y. H. Chen et al., "Risk factors for brain metastases in patients with renal cell carcinoma," BioMed Research International, vol. 2020, Article ID 6836234, 7 pages, 2020.

[22] W. Gui, W. Zhu, W. Lu et al., "Development and validation of a prognostic nomogram to predict overall survival and cancer- 
specific survival for patients with anaplastic thyroid carcinoma," PeerJ, vol. 8, article e9173, 2020.

[23] K. Chen, X. Deng, Z. Yang et al., "Survival nomogram for patients with metastatic siewert type II adenocarcinoma of the esophagogastric junction: a population-based study," Expert Review of Gastroenterology \& Hepatology, vol. 14, no. 8, pp. 757-764, 2020.

[24] X. Shang, H. Yu, J. Lin et al., "A novel nomogram including AJCC stages could better predict survival for NSCLC patients who underwent surgery: a large population-based study," Journal of Oncology, vol. 2020, Article ID 7863984, 9 pages, 2020.

[25] A. Pecoraro, C. Palumbo, S. Knipper et al., "Histologic subtype, tumor grade, tumor size, and race can accurately predict the probability of synchronous metastases in T2 renal cell carcinoma," Clinical Genitourinary Cancer, vol. 18, no. 5, pp. e610-e618, 2020.

[26] H. Lee, J. K. Lee, K. Kim et al., "Risk of metastasis for T1a renal cell carcinoma," World Journal of Urology, vol. 34, no. 4, pp. 553-559, 2016.

[27] B. Shuch, J. C. la Rochelle, T. Klatte et al., "Brain metastasis from renal cell carcinoma: presentation, recurrence, and survival," Cancer, vol. 113, no. 7, pp. 1641-1648, 2008.

[28] A. Suarez-Sarmiento Jr., K. A. Nguyen, J. S. Syed et al., "Brain metastasis from renal-cell carcinoma: an institutional study," Clinical Genitourinary Cancer, vol. 17, no. 6, pp. e1163e1170, 2019. 